\title{
Simulation of Rainfall Intensity and Slope Gradient to Determination the Soil Runoff Coefficient at Microplot Scale
}

\author{
Dawod Rasooli Keya ${ }^{1 *}$, Tariq H. Karim² \\ ${ }^{1}$ Department of Plant Production, Khabat Technical Institute, Erbil Polytechnic University, Erbil, Kurdistan Region, Iraq, ${ }^{2}$ Department of Soil and \\ Water, College of Agricultural Engineering Sciences, Salahaddin University, Erbil, Kurdistan Region, Iraq
}

\section{${ }^{*}$ Corresponding author: Dawod Rasooli Keya, Department of Plant \\ Production, \\ Khabat Technical Institute, Erbil Polytechnic University, Erbil, Kurdistan Region, Iraq. E-mail: dawod.keya@epu. edu.iq}

Received: 09 November 2019 Accepted: 11 May 2020

Published: 30 June 2020

\section{DOI}

10.25156/ptj.v10n1y2020.pp12-17

\section{A B S TR A C T}

Simulating rainfall is one of the valuable methods of measuring hydrological data and soil erosion processes. Rapid evaluation, high repeatability, and low cost are the reasons of using rain simulators. In this study, a rain simulator was constructed in dimensions of $3.0 \times 3.0 \times 3.0 \mathrm{~m}$ and it was protected on three sides by a plastic cover. An inclined table was used to create slopping surfaces of 5,10 , and $15 \%$. Microplots were used in the dimensions of $0.2 \times 0.4 \times 1.0 \mathrm{~m}$ to collect and measure direct runoff in a bucket outside the device. Nozzles were calibrated to produce two different rainfall intensities 10 and $20 \mathrm{mmh}^{-1}$ using sprinkler Model 5B at 8 and $12 \mathrm{psi}$, respectively. Furthermore, three different soil types, namely, clay loam (CL), silty clay (SC) loam, and SC were examined. In general, it was observed that with increasing the rainfall intensity and slope, the rate of runoff and sedimentation increase. SC soil at $15 \%$ slop offered the highest performance under the intensity of $20 \mathrm{mmh}^{-1}$. SC and the CL soils produced the highest and lowest runoff coefficients, respectively. The $\mathrm{CL}$ soil produced the highest soil loss $\left(1 \mathrm{kgm}^{2}\right.$ at $15 \%$ and I $\left.=20 \mathrm{mmh}^{-1}\right)$. Further, it was concluded that a significant change (an average increase of $53 \%$ ) in soil loss can be achieved as the rainfal intensity increased from 10 to $20 \mathrm{mmh}^{-1}$.

Keywords: Soil erosion; Rainfall simulator; Raindrop diameter; Runoff coefficient; Sedimentation

\section{INTRODUCTION}

Essentially, the study of water erosion under natural conditions is crucial, as it requires a long-term research program. Simulation of erosion factors on a small scale, with high repeatability, creates the opportunity to achieve results with less cost and time (Sushil et al., 2018). Rainfall simulators have been used to apply uniform rainfall rates over land surfaces or packed soil boxes to evaluate runoff under controlled conditions. Rainfall simulators were initially used to study soil erosion (Moussouni et al., 2012; Mutchler and Hermsmeier, 1965). To create artificial environment for rainfall research, rainfall simulators have been widely used as a research tool (Ellison and Pomerene, 1944; Mutchler and Hermsmeier, 1965; Laflen and Moldenhauer, 1979).

Rainfall simulators can be divided into two groups: Nonpressurized and pressurized simulators (Clarke and Walsh, 2007). In the non-pressurized nozzle rainfall simulators, droplets are mostly generated through hypodermic needles, polyethylene tube, and capillary tube (Chow and Harbaugh, 1965). Pressurized simulators use nozzles to initiate flow
(Imeson, 1977). A variety of rainfall simulators have been developed, which includes a small portable infiltrometer with a circular rainfall area of 6 inch diameter as well as the Kentucky rainfall simulator which covered a relatively large area of dimensions $4.5 \mathrm{~m}$ by $22 \mathrm{~m}$ (Moore et al., 1983).

As it is obvious from the Universal Soil Loss Equation (USLE), the rate of loosed soil is directly proportional to the rainfall intensity (erosivity power). In the same conditions, more intense rainfall causes more erosion. As well as, there is a close relationship between runoff and rainfall intensity. Many studies have been conducted on the relationship between rainfall intensity and runoff (Rajurkar et al., 2004; Anctil et al., 2006; Boughton, 2006; Jacquin and Shamseldin, 2006; Al-Qurashi et al., 2008; Bahat et al., 2009).

Along with the rainfall intensity, slope length (L), and gradient (S), which can be assessed through a combined LS factor (Wischmeier et al., 1958), are another two fundamental factors of erosion. The effect of slope length on erosion occurs through an increase in the volume and the speed of runoff, resulting in increased capacity of the 
runoff to disaggregate and transport sediments (Bagarello and Ferro, 2010).

The risk of erosion is affected by soil erodibility. Wischmeier and Smith (1978) used sand and silt fractions as indices for estimating the soil erodibility factor in the USLE model. Erodibility is low for clay-rich soils (ÓGeen et al., 2006), but height for sandy soils since they have a low cohesive force and are more prone to detachment and transportation by water and wind (Aba Idah et al., 2008). However, Duiker et al. (2001) stated that soil loss is negatively correlated with clay content but positively correlated with very fine sand and silt + very fine sand contents.

In the present study, the simultaneous influence of rainfall intensity, land slope, and soil type (soils surrounding Erbil city in terms of the particle size and compaction) on erosion and runoff generation was studied using a rainfall simulator.

\section{MATERIALS AND METHODS}

\section{Rainfall Simulator}

A rainfall simulator device has been manufactured with iron frame of $4 \times 4 \mathrm{~cm}$ and $3 \mathrm{~mm}$ in thickness and was assembled around a $3.0 \mathrm{~m}$ by $3.0 \mathrm{~m}$ level area with a coverage area of about $9 \mathrm{~m}^{2}$ and $3.5 \mathrm{~m}$ in height. The machine is portable as the frame structure can be opened and closed with screws. A plastic fabric is covering the outer surface in three sides to protect the rainfall simulator from wind effects. Figure 1 shows the general view of the simulator with associated components such as sprinkler manifolds, pump, and flow meter. All the rainfall simulation experiments were conducted over a selected area at the
Agricultural Research Center at Ainkawa, which is about $5 \mathrm{~km}$ to the northwest of Erbil city.

The water distribution was made by plastic pipes with a sprinkler system equipped with eight nozzles (Model 5B, commercial name). The spray angle was constant. The sprinklers were stationary and mounted over two lateral pipes, each carries four sprayers. The spacing along the lateral pipes was $0.70 \mathrm{~m}$, while the lateral spacing was $1.4 \mathrm{~m}$ [Figure 2]. An electric pump was used with one horsepower to create pressure on the system. The water gauge and manual valve installed for controlling rain speed. Two rates of rainfall intensity were created; 10 and $20 \mathrm{mmh}^{-1}$ at 8 and 12 psi, respectively. Calibration was done empirically by adjusting a flow meter in the line to control the inflow of water from the storage tank to ensure the required rainfall intensity. Calculation of raindrop diameter for rainfall simulator with varying intensity was studied according to Laws and Parsons (1943).

\section{Soil Samples}

Three soil samples with different texture were collected from the surface $0.30 \mathrm{~m}$. Samples were air-dried, nodule and coarse particles were broken up with a wooden hammer and passed through a 2-mm sieve. Physical characteristics of the soil samples were listed in Table 1.

Table 1: Particle size distribution for studied soils

\begin{tabular}{|c|c|c|c|c|c|c|}
\hline \multirow[t]{2}{*}{ No. } & \multicolumn{2}{|c|}{ Geographic coordinate } & \multicolumn{3}{|c|}{$\begin{array}{c}\text { Soil particle } \\
\text { distribution (\%) }\end{array}$} & \multirow{2}{*}{$\begin{array}{l}\text { Soil } \\
\text { texture } \\
\text { class }\end{array}$} \\
\hline & Latitude & Longitude & Sand & Clay & Silt & \\
\hline 1. & $36.144295^{\circ}$ & $44.020969^{\circ}$ & 23.25 & 28.50 & 48.25 & Clay loam \\
\hline 2. & $36.113581^{\circ}$ & $44.015567^{\circ}$ & 10.50 & 37.00 & 52.50 & $\begin{array}{l}\text { Silty clay } \\
\text { loam }\end{array}$ \\
\hline 3. & $36.245487^{\circ}$ & $43.994296^{\circ}$ & 13.50 & 42.50 & 44.00 & Silty clay \\
\hline
\end{tabular}

*Source: Keya, 2009

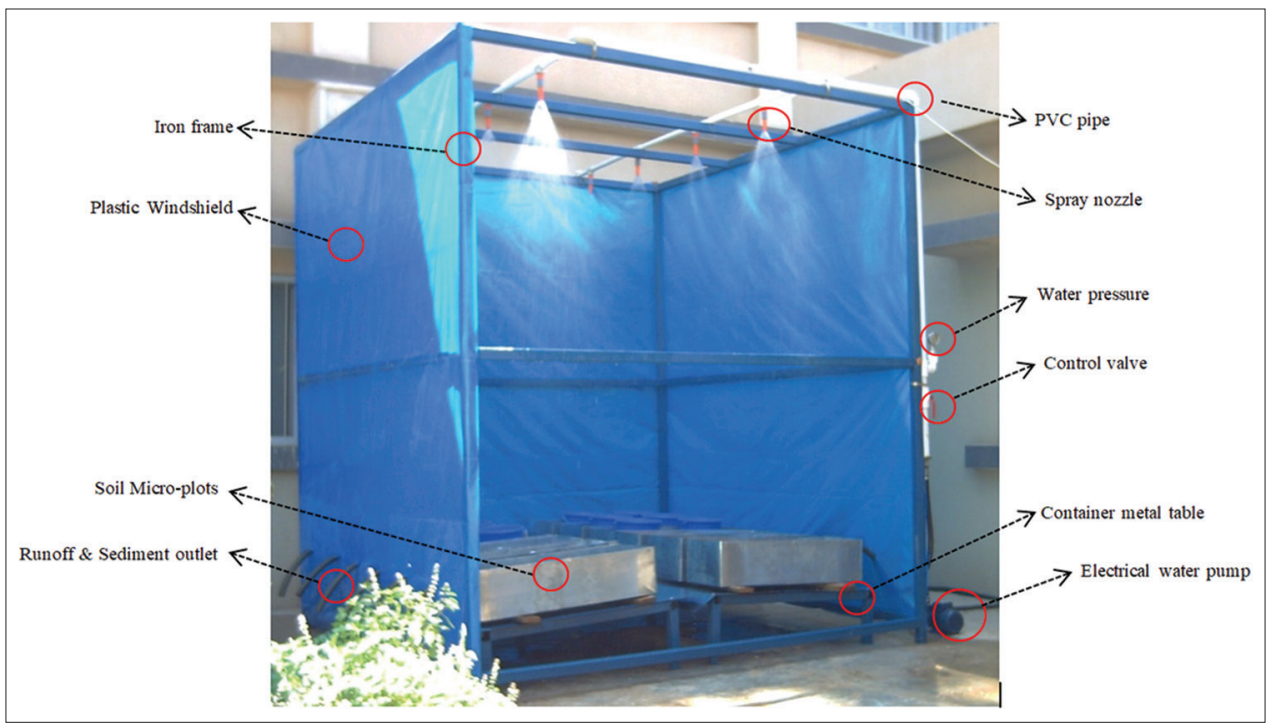

Figure 1: General view of rainfall simulator used in this study 


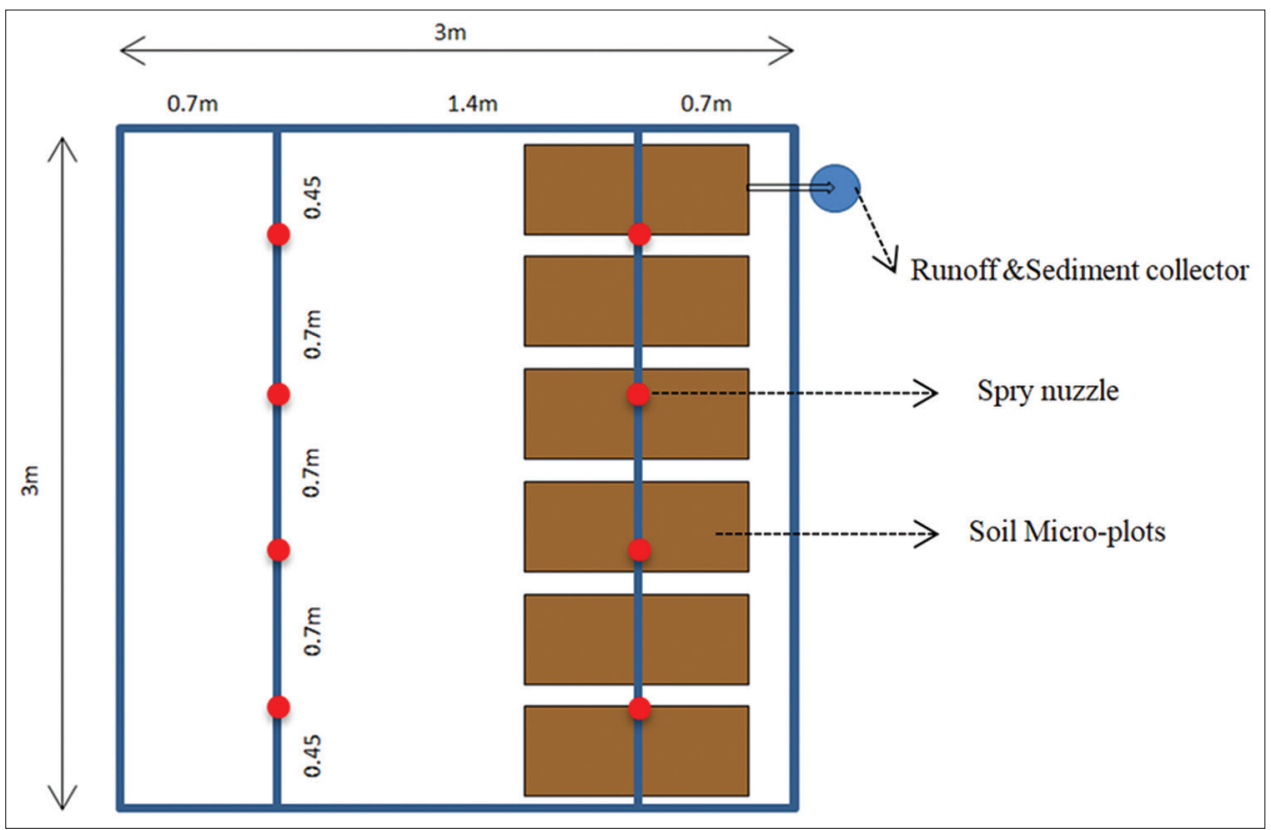

Figure 2: Layout of sprinkler system

\section{Microplots}

The handpicked soil samples were collected, mixed thoroughly, and moistened with a fine mist from a hand sprayer to raise the soil moisture content to optimum soil water content for compaction. Each soil sample packed in perforated trays $(1 \mathrm{~m} \times 0.40 \mathrm{~m} \times 0.2 \mathrm{~m})$ in form of three layers with a special wooden hammer designed for this purpose to achieve the bulk densities of $1.5,1.4$, and $1.3 \mathrm{Mgm}^{-3}$, respectively. These values approximate the in situ bulk densities of the investigated soils. The compacted soil was underlain by a perforated metal sheet to allow free drainage of percolated water. Before treating the soils and exposing them to rainfall, they were exposed to open air to attain near air-dry soil moisture content, as illustrated in Figure 3.

\section{Calibration and Uniformity Test}

The rainfall simulator used in this research was calibrated to give 10 and $20 \mathrm{mmh}^{-1}$ using available spraying nozzles at 8 and 12 psi, respectively. To ensure that the studying area is entirely covered and uniform rainfall over the tested area is properly achieved, the spray was captured by a grid-work of 3 inch stainless steel cans on the surface of the soils in the microplots. The volume of water was measured with a graduated cylinder recorded after operating the system for $1 \mathrm{~h}$. The microplots were placed under the rain with a slope ratio of 5,10 , and $15 \%$ by raising the upper part of plots.

Calibration was done empirically by adjusting a flow meter in the line to control the inflow of water from the storage tank to ensure the required rainfall intensity.

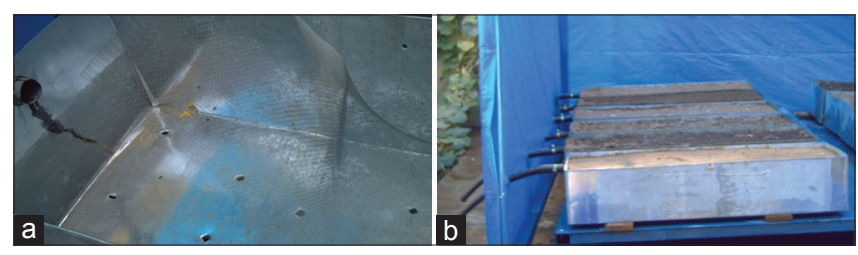

Figure 3: (a) holes and metal sheet in bottom of microplot, (b) prepared microplots under rainfall simulator

\section{Measurement of Runoff and Sediment}

A series of rainfall simulation experiments was conducted. The running water from the surface of microplots was driven from the outlet point by a hose toward the collection bucket, outside the windshield. After operating the system for $1 \mathrm{~h}$ (each replication), the volume of water was measured with a graduated cylinder and recorded as the runoff volume. The deposited soil was oven-dried and measured by a scale (accuracy \pm 1 ).

The experiment under rainfall simulator encompassed the study of a host of factors using three replicates. The factors were type of soil (three types), slope (three levels), and rainfall intensity (two levels). The responsible variables include runoff coefficient and soil loss were measured by:

$$
\text { Runoff coefficient }=V_{C W} / V_{R}
$$

Where; $V_{C W}$ is volume of collected water (lit) and $V_{R}$ is volume of rainfall in $1 \mathrm{~h}(\mathrm{l})$.

$$
\text { Soil loss }=S_{w} / A_{m}(\mathrm{Kg} / \mathrm{ha})
$$

Where; $S_{w}$ is Sediment weight and $A_{m}$ is Microplot area 
Each combination was replicated thrice. MS Excel program was used to analyze the results and generate graphs.

\section{RESULTS}

\section{Raindrop Diameter and Median Raindrop (D50)}

The obtained results are demonstrated in Figure 4 which shows that the correlation for both rainfall intensities examined in this study was close $\left(\mathrm{R}^{2}>95\right)$. The raindrop diameter varied from 0.56 to a maximum of $2.01 \mathrm{~mm}$, with an average of $1.5 \mathrm{~mm}$ at $10 \mathrm{mmh}^{-1}$, and 0.85 to $2.42 \mathrm{~mm}$ and the average diameter of the drops was $1.7 \mathrm{~mm}$ at an intensity of $20 \mathrm{mmh}^{-1}$. Further, as it can be seen in Figure 4, the median raindrop diameter was increased with increasing rainfall intensity. The same observation was made by (Laws and Parsons, 1943), (Hudson, 1995), and (Van Dijk et al., 2002). Table 2 presents the results of calculating the median raindrop $\left(\mathrm{D}_{50}\right)$ for two events. The raindrop size varied from 0.754 to $2.076\left(\mathrm{D}_{50}=1.2 \mathrm{~mm}\right)$ at an intensity of $10 \mathrm{mmh}^{-1}$ and from 0.742 to $2.421\left(\mathrm{D}_{50}=1.32 \mathrm{~mm}\right)$ at an intensity of $20 \mathrm{mmh}^{-1}$.

\section{Runoff Coefficient}

Figure 5 is the plot of runoff coefficient for three different soil types and three various slopes/gradients considered in this study. It is clear from this figure that as the clay content

Table 2: Calculation of $D_{50}$ for two events from rainfall simulator

\begin{tabular}{|c|c|c|c|c|c|c|c|c|c|c|c|c|}
\hline \multirow[t]{2}{*}{$\begin{array}{l}\text { Sieve size, } \\
\mathrm{mm}\end{array}$} & \multicolumn{2}{|c|}{$\begin{array}{l}\text { Number of pellets } \\
\text { retained on, }\end{array}$} & \multicolumn{2}{|c|}{$\begin{array}{l}\text { Average pellet } \\
\text { mass, mg }\end{array}$} & \multicolumn{2}{|c|}{$\begin{array}{l}\text { Average mass } \\
\text { ratio }\end{array}$} & \multicolumn{2}{|c|}{$\begin{array}{l}\text { Average mass of } \\
\text { drop, } \mathrm{mg}\end{array}$} & \multicolumn{2}{|c|}{$\begin{array}{l}\text { Average drop } \\
\text { diameter, } \mathrm{mm}\end{array}$} & \multicolumn{2}{|c|}{$\mathrm{D}_{50}, \mathrm{~mm}$} \\
\hline & $I_{1}$ & $I_{2}$ & $I_{1}$ & $I_{2}$ & $I_{1}$ & $I_{2}$ & $I_{1}$ & $I_{2}$ & $I_{1}$ & $\mathrm{I}_{2}$ & $I_{1}$ & $\mathrm{I}_{2}$ \\
\hline 3 & 5 & 3 & 4.820 & 7.740 & 0.972 & 0.960 & 4.685 & 7.430 & 2.076 & 2.421 & 1.2 & 1.32 \\
\hline 2 & 10 & 5 & 4.480 & 5.140 & 0.975 & 0.970 & 4.368 & 4.986 & 2.028 & 2.119 & & \\
\hline 1.4 & 99 & 86 & 1.890 & 2.310 & 1.010 & 0.993 & 1.909 & 2.294 & 1.539 & 1.636 & & \\
\hline 1 & 159 & 181 & 0.990 & 1.350 & 1.025 & 1.020 & 1.015 & 1.377 & 1.247 & 1.380 & & \\
\hline 0.5 & 82 & 214 & 0.210 & 0.200 & 1.070 & 1.070 & 0.225 & 0.214 & 0.754 & 0.742 & & \\
\hline
\end{tabular}

$\mathrm{I} 1=10 \mathrm{mmh}^{-1}$ and $\mathrm{I} 2=20 \mathrm{mmh}^{-1}$
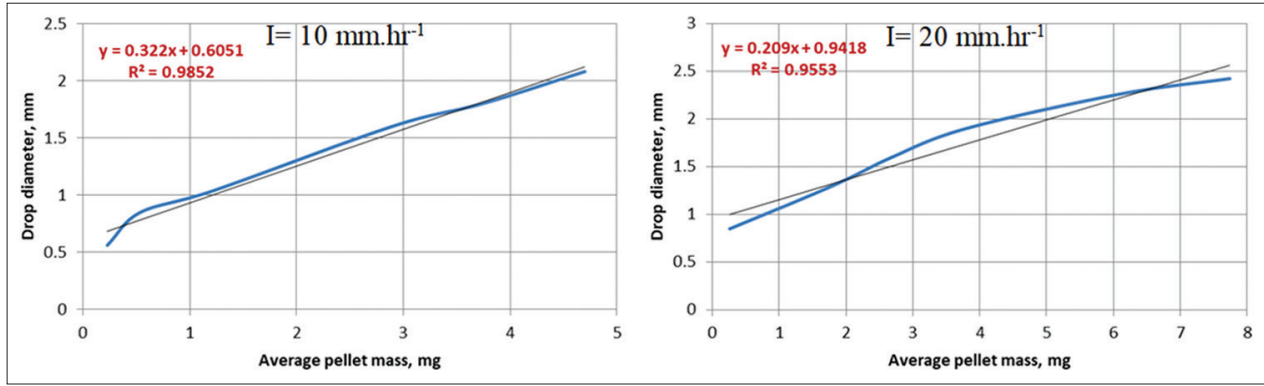

Figure 4: Correlation between the raindrop diameter and the rainfall intensity

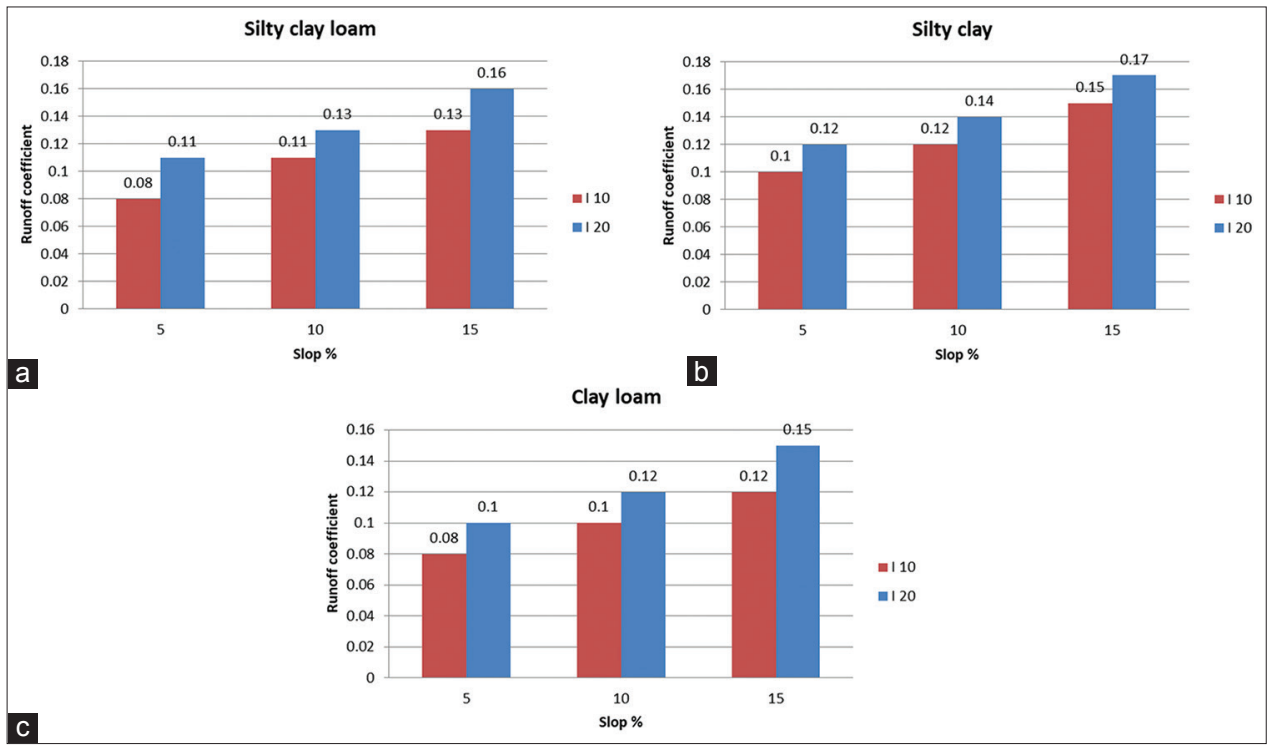

Figure 5: (a-c) Replotting the runoff coefficient under simulated rainfall with two different intensities as affected by type of soil, for different land slopes/gradients 
increased from $28 \%$ to $42 \%$ a very slight change in runoff coefficient occurred. Furthermore, a very slight change in runoff coefficient was observed. The results indicated that the overall runoff coefficient ranged from a minimum of 0.079 for the $5 \%$ slop and silty clay loam (SCL) soil to a maximum of 0.153 for the slop $15 \%$ and SCL soil at rainfall intensity of $10 \mathrm{mmh}^{-1}$, and from a minimum of 0.105 for $5 \%$ slop and clay loam (CL) soil to a maximum of 0.173 for 15\% slop and silty clay (SC) soil at rainfall intensity of $20 \mathrm{mmh}^{-1}$. Therefore, it can be concluded that the SC soil at $15 \%$ slop provided the highest performance under the rainfall intensity of $20 \mathrm{mmh}^{-1}$.

However, it was found that the SC and the CL soils produced the highest and lowest runoff coefficients, respectively, and those of SCL were intermediate between those of the abovementioned soils. This conclusion is true under different land slopes and two rainfall intensities.

\section{Sediment Yield}

According to the results tabulated in Table 3, it can be noticed that for a given land slope/gradient and rainfall intensity, the CL soil produced the highest soil loss. Similar results have been obtained in the researches of (Xinliang and Zhiyuan, 2017), Defersha and Melesse (2012). This

\begin{tabular}{|c|c|c|c|}
\hline \multicolumn{4}{|c|}{ Sediment yield or soil loss (unit) } \\
\hline Soil type & Slop \% & $I_{10}$ & $I_{20}$ \\
\hline \multirow[t]{3}{*}{ SCL } & 5 & 83.0 & 150.3 \\
\hline & 10 & 194.2 & 351.8 \\
\hline & 15 & 262.2 & 474.9 \\
\hline \multirow[t]{3}{*}{ SC } & 5 & 90.0 & 155.7 \\
\hline & 10 & 228.6 & 395.4 \\
\hline & 15 & 288.0 & 498.2 \\
\hline \multirow[t]{3}{*}{$C L$} & 5 & 278.3 & 378.8 \\
\hline & 10 & 592.9 & 806.9 \\
\hline & 15 & 735.1 & 1000.6 \\
\hline
\end{tabular}

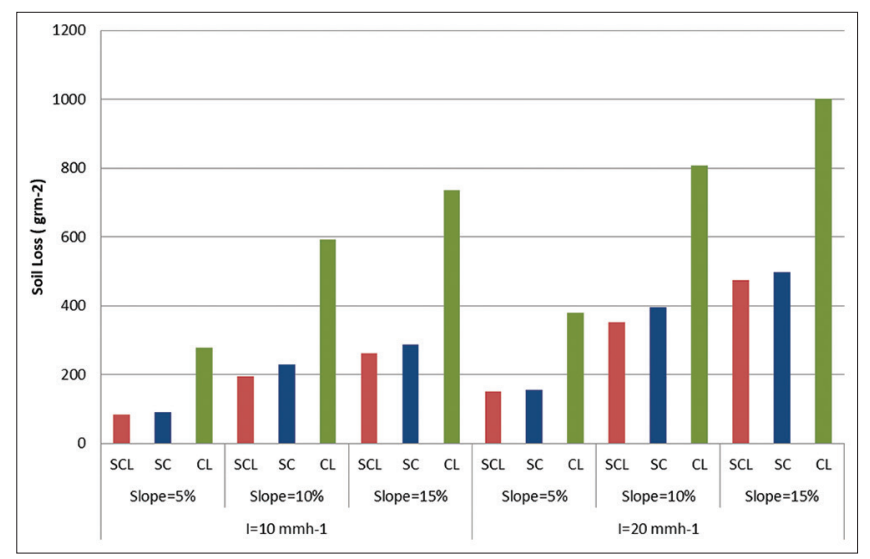

Figure 6: Soil loss from microplots subject to artificial rainfall as influenced by land slope, rainfall intensity, and soil type may be due to the higher silt content of this soil compared with the other two soil types. Previously published studies reported that the soil erodibility increases when silt and fine sand fractions increase and clay content decreases (Le Bissonnais, 1996, Romkens et al., 1977; and Bradford and Huang, 1992).

It is also evident from the obtained results that a significant change in soil loss was brought about as the rainfall intensity increased from 10 to $20 \mathrm{mmh}^{-1}$.

However, as shown in Figure 6, it can be seen that as the land slope increased from $5 \%$ to $15 \%$, there is a continuous increase in soil loss while keeping other factors constant. This can be attributed to the fact that infiltration rate is greatly increased at a higher intensity. Furthermore, the results of this study agree well with (Liu et al., 1994) whom indicated that the soil loss is directly affected by slope gradient. In addition, Wenbin et al., 2015 reported that there was a strong relationship between rainfall intensity, slope gradient, and runoff.

\section{CONCLUSION}

Based on the obtained results from the current study, it can be concluded that the runoff coefficient was increased with an increase in clay content. This conclusion is true under different land slopes and two rainfall intensities. The results also indicated that the runoff coefficient increased with an increase in the land slope in all the study soils, but the increase in slope brought an insignificant change in runoff.

Furthermore, there is indication of an increase in the effectiveness of slope on increasing runoff coefficient with an increase in rainfall intensity from 10 to $20 \mathrm{mmh}^{1}$.

\section{REFERENCES}

Aba Idah, P., H. I. Mustapha, J. J. Musa and J. Dike. 2008. Determination of erodibility in dices of soils in Owerri west local government area of Imo State Nigeria. Assumption Univ. J. Technol. 12: 130-133.

Al-Qurashi, A., N. Mclntyre, H. Wheater and C. Unkrich. 2008. Application of the Kineros2 rainfall runoff model to an arid catchment in Oman. J. Hydrol. 355: 91-105.

Anctil, F. O., N. Lauzon, V. Andre'assian, L. Oudin and C. Perrin. 2006. Improvement of rainfall runoff forecasts through mean areal rainfall optimization. J. Hydrol. 328: 717-725.

Bagarello, V. and V. Ferro. 2010. Analysis of soil loss data from plots of differing length for the Sparacia experimental area Sicily Italy. Biosyst. Eng. 105: 411-422.

Bahat, Y., T. Grodek, J. Lekach and E. Morin. 2009. Rainfall-runoff modeling in a small hyper-arid catchment. J. Hydrol. 373: 204-217.

Boughton, W. 2006. Calibrations of a daily rainfall-runoff model with poor quality data. Environ. Model. Softw. 21: 1114-1128. 
Bradford, J. M. and C. Haug. 1992. Mechanisms of crust formation: Physical components. In: sumner, M. E. and Stewart, B. A. editors. Advances in Soil Science, Soil Crusting: Physical and Chemical Processes. Lewis Publi, Boca Roton. p55-72.

Chow, V. T. and T. E. Harbaugh. 1965. Raindrop production for laboratory watershed experimentation. J. Geophys. Res. 70: 6111-6119.

Clarke, M. A. and R. P. D. Walsh. 2007. A portable rainfall simulator for field assessment of splash and slope wash in remote locations. Earth Surf. Proc. Land. 32: 2052-2069.

Defersha, M. B. and A. M. Melesse. 2012. Effect of rainfall intensity, slope and antecedent moisture content on sediment concentration and sediment enrichment ratio. Catena. 90: 47-52.

Duiker S. W., D. C. Flanagan and R. Lal. 2001. Erodibility and infiltration characteristics of five major soils of southwest Spain. Catena. 45: 103-121.

Ellison, W. D. and W. H. Pomerene. 1944. A rainfall applicator. Agric. Eng. 25: 220.

Hudson, N. 1995. Soil Conservation. $3^{\text {rd }}$ ed. BT Batsford, London. p391.

Imeson, A. C. 1977. A simple field-portable rainfall simulator for difficult terrain. Earth Surf. Process. 2: 431-436.

Jacquin, A. P. and A. Y. Shamseldin. 2006. Development of rainfallrunoff models using Takagi-Sugeno fuzzy inference systems. J. Hydrol. 329: 154-173.

Keya, D. R. 2009. Determination of Catchment Area to Cultivated Area Ratio for Crop Production System in Arbil Governorate. Submitted to College of Agriculture, University of Salahaddin. As a Partial Fulfillment of the Requirement of M.Sc. Thesis.

Laflen, J. M. and W. C. Moldenhauer. 1979. Soil and water losses from corn-soybean rotation. Soil Sci. Soc. Am. J. 43: 1213-1215.

Laws, J. O. and D. A. Parsons. 1943. The Relation of Raindrop Size to Intensity. Transactions of American Geophysical Union, 24 ${ }^{\text {th }}$ Annual Meeting. p452-460.

Le Bissonnais, Y. 1996. Aggregate stability and assessment of soil crustability and erodibility: I. Theory and methodology. Eur. J. Soil Sci. 47: 425-437.
Liu, B. Y., M. A. Nearing and L. M. Risse. 1994. Slope gradient effects on soil loss for steep slopes. Trans. ASAE. 37: 1835-1840.

Moore, I. D., P. E. Gessle, G. A. Nielson and G. A. Peterson. 1993. Soil attributes prediction using terrain analysis. Soil Sci. Soc. Am. J. 57: 443-452.

Moussouni, A., L. Mouzai and M. Bouhadef. 2012. Laboratory experiments: Influence of rainfall characteristics on runoff and water erosion. J. World Acad. Sci. Eng. Technol. 68: 1540-1543.

Mutchler, C. K. and L. F. Hermsmeier. 1965. A review of rainfall simulators. ASAE Trans. 8: 63-65.

ÓGeen, A. T., R. Elkins and D. Lewis. 2006. Erodibility of Agricultural Soils with Examples in Lake and Mendocino Counties Oakland. University of California, Division of Agriculture and Natural Resources, Publication No. 8194.

Rajurkar, M. P., U. C. Kothyari and U. C. Chaube. 2004. Modeling of the daily rainfall-runoff relationship with artificial neural network. J. Hydrol. 285: 96-113.

Romkens, M. J. M., C. B. Rose and D. W. Nelson. 1977. Erodibility of selected clay subsoils in relation to physical and chemical properties. Soil Sci. Soc. Am. J. 41: 954-960.

Sushil, N. M., P. Khanindra and B. Arnab. 2018. A comprehensive design of rainfall simulator for the assessment of soil erosion in the laboratory. CATENA. 172: 408-420.

Van Dijk, A. I. J., L. A. Bruijnzeel and C. J. Rosewell. 2002. Rainfall intensity kinetic energy relationships: A critical literature appraisal. J. Hydrol. 261: 1-23.

Wenbin, M., Y. Fuliang, C. Li and N. Zhao. 2015. Effects of rainfall intensity and slope gradient on runoff and soil moisture content on different growing stages of spring maize. Water. 7: 2990-3008.

Wischmeier, W. H. and D. D. Smith. 1978. Predicting Rainfall Erosion Losses: A Guide to Conservation Planning Agricultural Handbook. Vol. 537. US Department of Agriculture, Washington, DC.

Wischmeier, W. H., D. D. Smith and R. E. Uhland. 1958. Evaluation of factors in the soil-loss equation. Agric. Eng. 39: 458-462.

Xinliang, W. and W. Zhiyuan. 2017. Effects of erosion degree and rainfall intensity on erosion processes for Ultisols derived from quaternary red clay. Agric. Ecosyst. Environ. 249: 226-236. 